\title{
Off-pump repair of a post-infarct ventricular septal defect: the 'Hamburger procedure' Thomas A Barker*1, Alexander $\mathrm{Ng}^{2}$ and Ian S Morgan ${ }^{1}$
}

Address: ${ }^{1}$ Department of Cardiothoracic Surgery, Heart and Lung Centre, Wolverhampton, UK and ${ }^{2}$ Department of Cardiothoracic Anaesthesia, Critical Care \& Pain Management, Heart and Lung Centre, Wolverhampton, UK

Email: Thomas A Barker* - tombarker@doctors.org.uk; Alexander Ng - Alexander.Ng@rwh-tr.nhs.uk; Ian S Morgan - Ian.Morgan@rwh-tr.nhs.uk

* Corresponding author

Published: 12 May 2006

Journal of Cardiothoracic Surgery 2006, I:10 doi:10.1 I86/1749-8090-1-10
Received: 10 March 2006

Accepted: 12 May 2006

This article is available from: http://www.cardiothoracicsurgery.org/content/I/I/I0

(c) 2006 Barker et al; licensee BioMed Central Ltd.

This is an Open Access article distributed under the terms of the Creative Commons Attribution License (http://creativecommons.org/licenses/by/2.0), which permits unrestricted use, distribution, and reproduction in any medium, provided the original work is properly cited.

\begin{abstract}
We report a novel off-pump technique for the surgical closure of post-infarct ventricular septal defects (VSDs). The case report describes the peri-operative management of a 76 year old lady who underwent the 'Hamburger procedure' for closure of her apical VSD. Refractory cardiogenic shock meant that traditional patch repairs requiring cardiopulmonary bypass would be poorly tolerated. We show that echocardiography guided off-pump posterior-anterior septal plication is a safe, effective method for closing post-infarct VSDs in unstable patients. More experience is required to ascertain whether this technique will become an accepted alternative to patch repairs.
\end{abstract}

\section{Introduction}

Ventricular septal defect (VSD) is a rare but significant complication following myocardial infarction. Medical management alone is inadequate, and although recent advances in transcatheter closure have been promising [1], surgical repair if often the only option. Various surgical techniques have been described including single or double patch procedures with infarct exclusion $[2,3]$. These open procedures require the use of cardiopulmonary bypass (CPB) and 30-day mortality ranges from 23 to $42 \%[3,4]$.

Recently, an off-pump closure technique called the 'Hamburger procedure' has been pioneered as an alternative to open procedures that require CPB and ventriculotomy [5]. The aim of our report is to describe how a post-infarct VSD may be repaired without CPB and to highlight the importance of echocardiography to guide VSD closure.

\section{Case report}

A 76 year-old female smoker was thrombolyzed with Tenecteplase after an acute anterior myocardial infarction. Unfortunately she remained hypotensive and so she underwent emergency angiography which showed patent coronary arteries except for the left anterior descending artery which was occluded distally. After this procedure she was noted to have a pansystolic murmur and transthoracic echocardiography (TTE) using a Vivid 7 Pro (GE Vingned, Norway), confirmed a $1 \mathrm{~cm}$ antero-apical VSD and an akinetic ventricular apex.

To manage her hypotension inotropes were commenced and an intra-aortic balloon pump was inserted. After stabilization for 5 days, diuretics and nitrates were added for progressing pulmonary oedema. Repeat TTE images showed no change, and although the right ventricle was mildly dilated, global left ventricular function was preserved. A decision was made to perform a delayed surgical repair to reduce operative risk. 


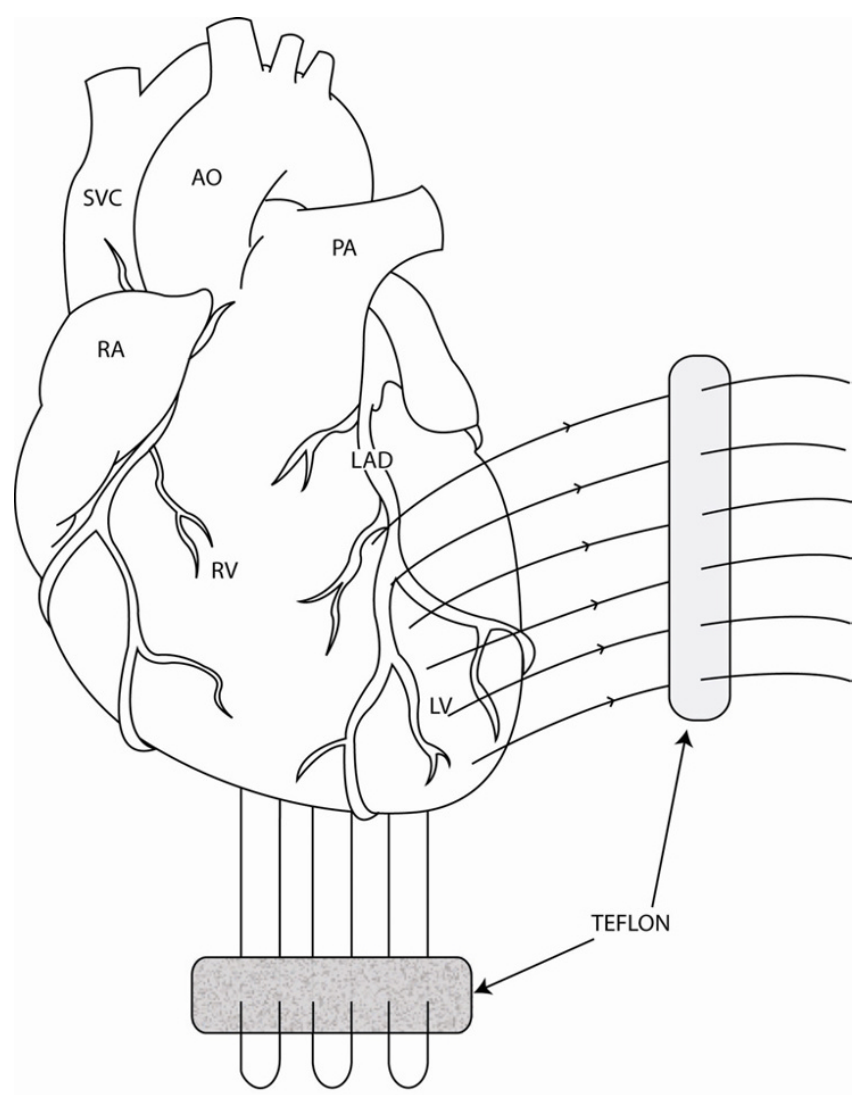

Figure I

Diagram of the heart demonstrating suture position for the 'Hamburger procedure'. AO = aorta, LAD = left anterior descending artery, $L V=$ left ventricle, $P A=$ pulmonary artery, $\mathrm{RA}=$ right atrium, $\mathrm{RV}=$ right ventricle, $\mathrm{SVC}=$ superior vena cava.

She was reviewed in the local multi-disciplinary meeting and transcatheter closure was not thought to be appropriate. Four weeks after admission, she developed short episodes of ventricular tachycardia which were controlled by amiodarone. Two days later she deteriorated becoming hypotensive with worsening pulmonary oedema. She became hypoxic and hypercarbic and dobutamine infusion was added along with an escalation in her diuretic therapy. Sedation and mechanical ventilation were then required. Repeat TTE remained unchanged. A pulmonary artery flotation catheter was inserted and norepinephrine was commenced to treat persistent hypotension. Renal function began to deteriorate with serum creatinine rising to $190 \mu \mathrm{mol} \mathrm{l^{-1 }}$.

Thirty days after myocardial infarction, she underwent an off-pump 'Hamburger' post-infarct VSD repair. The heart was approached through a median sternotomy and a posterior-anterior septal plication was performed using three double-armed Teflon felt supported interrupted 1.0
Ticron sutures (Syneture ${ }^{\mathrm{TM}}$, USA). The Teflon strip was preloaded with sutures and from below the needles were passed through the posterior (inferior) interventricular septum aiming for the anterior part of the septum where the tip of the needle is retrieved. The sutures run just lateral to the LAD to ensure plicating the thicker left ventricular wall rather than the thinner right ventricular wall (Figure 1). The needles were then passed through the second Teflon strip and then tied starting at the apex and working more proximally (Figure 2). VSD closure was assessed using transesophageal (Figure 3) and epicardial echocardiography as well and by epicardial auscultation.

Soon after surgery, she began to improve and her inotropes and frusemide were discontinued. However she required a tracheotomy to facilitate weaning from mechanical ventilation. She was transferred to a rehabilitation facility 4 weeks after the operation. She was found to be asymptomatic and mobilising independently at 6 month follow-up.

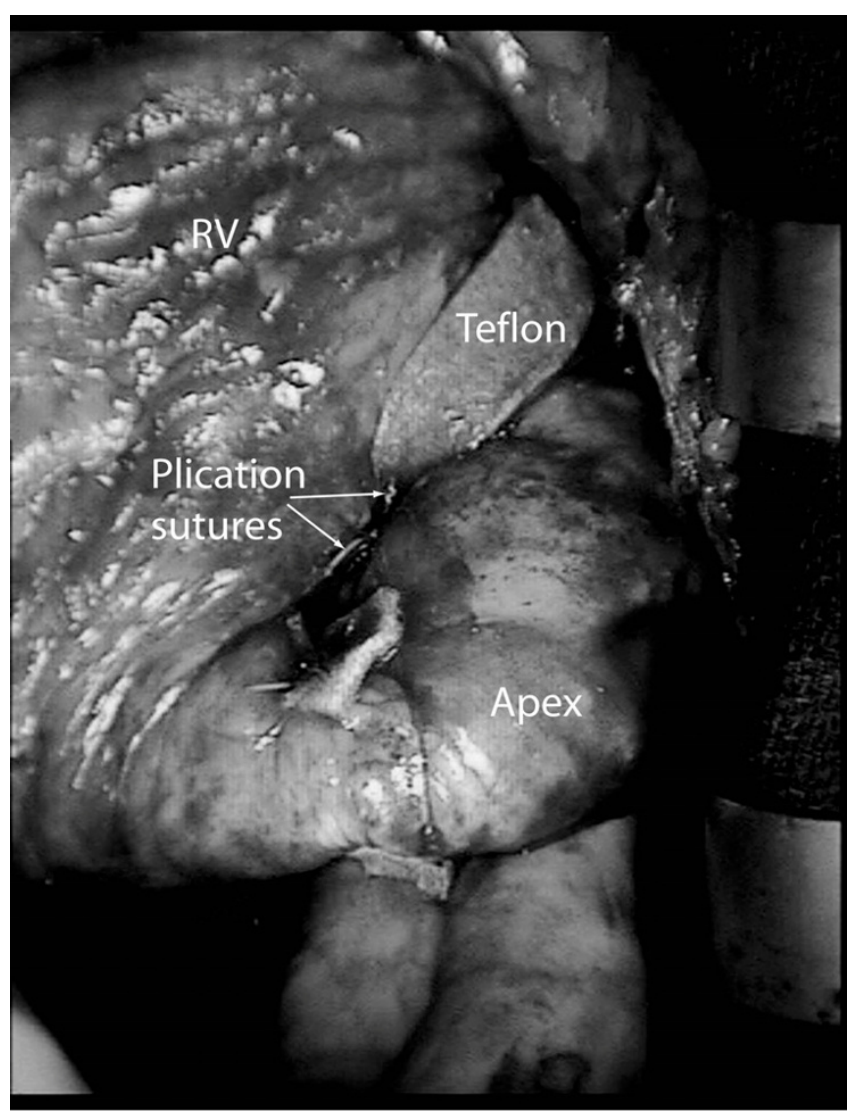

Figure 2

Operative photograph of the heart following the 'Hamburger procedure'. 


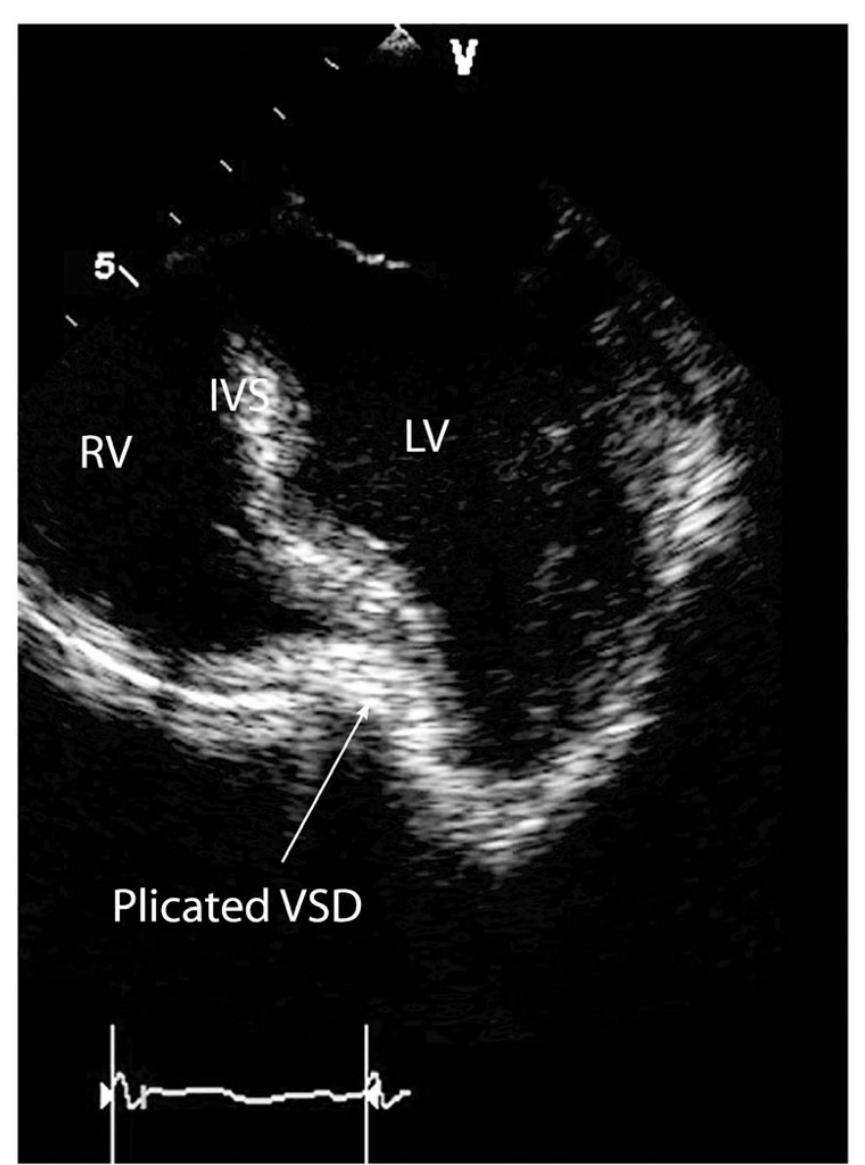

Figure 3

Mid-esophageal, 4 chamber, 2D Transoeophageal echocardiogram showing septal plication. IVS = interventricular septum.

\section{Comment}

Here we show that the 'Hamburger procedure' was an effective method for repair of a post-infarct VSD. By bringing the left and right ventricles into close apposition with Teflon supported plication sutures, the defect was closed with moderate reductions in cardiac chamber size. A dramatic reduction in pulmonary arterial pressure and inotropic doses occurred immediately after surgery. As our technique was performed off-pump, potential sequelae of CPB (ie adverse haemodynamic, neurological and inflammatory effects) were obviated. This lady benefited from a short operative time of 40 minutes compared with a longer, more complex open patch repair requiring $\mathrm{CPB}$ and ventriculotomy.

One important factor associated with poor outcome is a short VSD to operation time [6]. Surgery was postponed for 4 weeks which allowed the fibrotic process in the infarcted myocardium to become established. This delay helped in allowing the Teflon supported plication sutures to hold. It is uncertain whether the friable myocardium would have supported such sutures if surgery was performed sooner.

We demonstrate that echocardiography is not only essential in the diagnosis of post-infarct VSDs but also plays an important role in guiding VSD closure when the 'Hamburger procedure' is utilized. In this case, extra sutures were added to the initial plication after echocardiography had demonstrated that VSD closure was incomplete. Both transoesophageal and epicardial imaging enabled us to ensure that successful closure was achieved. TTE was used in the post-operative period to show that there was no residual VSD prior to discharge.

The 'Hamburger procedure' is a promising alternative method for post-infarct VSD repair. It appears to be suitable in patients with a VSD in the antero-apical septal position. We feel this technique would not be appropriate for posterior VSDs or VSDs higher up the septum closer to the atrioventricular valves. A randomised controlled trial would be needed to compare outcomes after this technique with those after conventional methods. VSD recurrence rates, functional outcome and mortality would be important factors that could be assessed. In this case, we believe that the risk of morbidity and mortality was reduced by avoiding $\mathrm{CPB}$ and therefore we are confident that the 'Hamburger Procedure' may become an accepted and useful technique in the future.

\section{Acknowledgements}

We would like to acknowledge the work of Mr A Wood based at St Bartholomew's Hospital, London, UK. He initially pioneered this off-pump VSD closure technique and should therefore be credited with the initial experience of this procedure. Also we would like to thank Ms Naseeba Hussain for help with preparation of the images.

\section{References}

I. Mullasari AS, Umesan CV, Krishnan U, Srinivasan S, Ravikumar M, Raghuraman H: Transcatheter closure of post-myocardial infarction ventricular septal defect with Amplatzer septal occluder. Catheter Cardiovasc Interv 200I, 54(4):488-489.

2. Chang YL, Hsu CP, Lai ST, Yu TJ, Hwang JH, Shih CT, Yung MC, Chang SH, Wang JS: Surgical techniques for emergent repair of post-infarction ventricular septal defect: compare endocardial patch and infarct exclusion method with traditional method. J Chin Med Assoc 2003, 66(I 2):722-726.

3. Labrousse L, Choukroun E, Chevalier JM, Madonna F, Robertie F, Merlico F, Coste P, Deville C: Surgery for post infarction ventricular septal defect (VSD): risk factors for hospital death and long term results. Eur J Cardiothorac Surg 2002, 2I(4):725-73I.

4. Barker TA, Ramnarine IR, Woo EB, Grayson AD, Au J, Fabri BM, Bridgewater B, Grotte GJ: Repair of post-infarct ventricular septal defect with or without coronary artery bypass grafting in the northwest of England: a 5-year multi-institutional experience. Eur J Cardiothorac Surg 2003, 24:940-946.

5. Chikwe J, Morgan IS, Wood A: Off-Pump Repair Of Postinfarction Ventricular Septal Defect. Abstract presented at the International Society for Minimally Invasive Cardiothoracic Surgery 8th Annual Meeting 2005. 
6. Mantovani V, Mariscalco G, Leva C, Blanzola C, Sala A: Surgical repair of post-infarction ventricular septal defect: 19 years of experience. Int J Cardiol 2005 in press.

Publish with Bio Med Central and every scientist can read your work free of charge

"BioMed Central will be the most significant development for disseminating the results of biomedical research in our lifetime. " Sir Paul Nurse, Cancer Research UK

Your research papers will be:

- available free of charge to the entire biomedical community

- peer reviewed and published immediately upon acceptance

- cited in PubMed and archived on PubMed Central

- yours - you keep the copyright

Submit your manuscript here:

http://www.biomedcentral.com/info/publishing_adv.asp 